\title{
Use of Automatic Identification System (AIS) data to study patterns of navigation behavior in the Macapá and Santana / AP / Brazil Ship Monitoring Area $(\mathrm{AMN})$
}

\begin{abstract}
The Amazon estuary is a poorly studied region in relation to the traffic safety of vessels in congested areas, such as ports, estuaries and coastal waters. It is of relevance and public interest to understand navigation operations and the risks presented by this activity to society generally. Studies on the subject in the Amazon are also very rare. The objective of this study is to statistically evaluate the navigation behavior in this region, using the online Automatic Identification System (AIS) database obtained from the site https://www.marinetraffic.com. As a result, the AIS data were tested by accepting the hypothesis that there are considerable risks of local navigation operations, depending on the behavior observed in the region, and especially regarding the frequency of average or instantaneous speeds practiced above what is legally permitted $(\mathrm{p}<0.05)$. The present study is an unprecedented and valuable source of research on the navigation behavior of ships in the Amazonian estuary. In addition, it offers the possibility of recognizing some behavioral patterns of ships traveling on this waterway, and it is also possible to classify such behaviors according to technical criteria based on internationally recognized information to monitor ships of various categories and draft. Therefore, the information obtained can help port managers and environmental protection authorities in making operational decisions related to potential risks of accidents or complex situations involving the interaction between both areas.
\end{abstract}

Keywords: Amazon biodiversity, brazilian laws, bioinvasions, ships behavior, Amazon river
Volume 8 Issue 3 - 2019

\author{
José Pinheiro Fragoso Neto Pereira,' \\ Newton Narciso Pereira, ${ }^{2}$ Alan Cavalcanti da \\ Cunha ${ }^{3}$ \\ 'UEAP University of the State of Amapá, Macapá, Amapá, Brazil \\ ¿UNIFAP Federal University, Macapá,Amapá, Brazil \\ ${ }^{3}$ UFF Federal Fluminense University, Volta Redonda, Rio de \\ Janeiro, Brazil
}

\begin{abstract}
Correspondence: José Pinheiro Fragoso Neto Pereira, UEAP University of the State of Amapá, Macapá,Amapá, 68900000, Brazil,Email el_neton@hotmail.com
\end{abstract}

Received: June 15, 2019 | Published: June 25, 2019

\section{Introduction}

Water transport offers the most efficient means of transporting large quantities of goods over long distances. The central role of maritime transport in the global logistics system is evident in the International Maritime Organization (IMO) statistical estimates, where about $90 \%$ of world trade is transported by waterways and trade volume is still growing at an even faster rate than the global economy. ${ }^{1-3}$ The growth of the world economy and trade, therefore, translates into a growing demand for more ships with higher carrying capacity and greater speed of movement and highlights maritime safety concerns, which tends to increase the risks of accidents and collisions with all their potential consequences. ${ }^{4}$ Four countries (Japan, Greece, Germany and China) own and control about $50 \%$ of the world's gross tonnage. However, between $60 \%$ (China) and 93\% (Japan) of this tonnage are registered under a foreign flag - most of them known as "open registries" or "flags of convenience". Flags of convenience are generally less concerned about and sensitive to environmental protection and to labor, safety, and tax standards. In $2009,52 \%$ of total deadweight tonnage was registered under six flags of convenience (Panama, Liberia, Marshall Islands, Bahamas, Malta and Cyprus). ${ }^{5}$

Most ship owners and operators choose to comply with international safety and environmental standards. The real problem lies in a relatively small percentage of ships and owners who persist in consistently operating their ships in total contravention of international safety and environmental standards. It is estimated that between 5,000 and 7,500 precarious commercial vessels are polluting the seas through their non-compliance with international environmental regulations. ${ }^{6}$

For safe and efficient movement, ships must adapt to their navigation environment. Therefore, vessel traffic behavior characteristics include vessel behavior, vessel behavior distribution and other dynamic characteristics that reflect vessel movement patterns. In other words, the behavioral characteristics of vessel traffic consist of macro behavioral and micro behavioral characteristics. ${ }^{7,8}$

Emissions from shipping such as shipboard waste, sewage (ash), fuel and oil by-products, ballast water and improper handling of dangerous products in ports endanger human health of rising coastal populations, biological diversity - bio invasions - golden mussel ${ }^{3}$ and natural resources in sensitive coastal areas, as well as livelihoods from coastal fisheries to tourism, threaten biological diversity, natural resources and human health in communities close to ports, coastal communities, in regions along inland waterways. ${ }^{59} \mathrm{~A}$ fraction of the conventional pollutants produced by navigation, such as sulfur oxides, nitrogen oxides and particulates are released away from land; it is estimated that 70 to $80 \%$ of this pollution is released within $400 \mathrm{~km}$ of the coast. ${ }^{10}$ In 2012, global vessel traffic accounted for $2.2 \%$ of global $\mathrm{CO}_{2}$ emissions. ${ }^{4}$ For this reason, Liquefied Natural Gas (LNG) is gaining popularity as a fuel in the merchant industry as it dramatically 
reduces NOx emissions, virtually eliminates SOx and particulate emissions, including carbon black, and can also reduce emissions. ${ }^{11}$

In ports, officers monitor the traffic patterns of various surveillance media, identify suspect patterns or possible collisions, and generate alerts. Advanced ports, such as the Port of Singapore, use the Ship Traffic Management System to gather real-time vessel information - a database of fusion vessels, navigation data, and surveillance of electrooptical cameras. Other trained officers then monitor the information displayed in search of safety risk standards to prevent undesirable actions from suspect ships and / or non-compliant activities. ${ }^{12}$

Incidents that may occur in merchant shipping operations involve risks such as fires, landfills, collisions, loss of property, spillage of hazardous substances or pollutants, and present various risks of human interference, such as erosion processes and other environmental and economic impacts. In addition, the growth of the world fleet, both in number of vessels and in tonnage of cargoes, consequently, leads to an increase in the indices of records of occurrences or incidents between ships. ${ }^{13-15}$

As a result of this reality, AIS data have become an important source of information for the study of maritime traffic and associated risks, in particular risk of collision between ships that can release pollutants into the water. ${ }^{16-18}$ As more vessels operate in the Amazon region, there is a tendency to increase the risk of incidents that negatively affect the aquatic environment. ${ }^{19}$ The effects of the increased traffic on ships include: oil spills, emissions, operational discharges, invasive species, noise and collisions of ships with marine mammals and other species. ${ }^{3,19,20}$

The risks of commercial water transport are faced by a large number of regulations, safety practice protocols and navigation technologies, which have made this mode of transportation in Brazil and globally much safer in recent decades. ${ }^{21}$ Commercial water transport operates in a complex risk environment where a variety of factors such as congested pathways, weather and navigability, equipment failures, human failures, pirate attacks, cyber-attacks, these factors interact to increase or decrease the probability of an accident and the severity of its impact. ${ }^{22}$

But the nature of the risk of commercial water transport varies by region due to differences in cargo, regulation, physical characteristics of the aquatic environment, and economic, social and cultural uses of waterways and the coast. Better quality, statistically analyzed sea transport data are required to minimize the likelihood of incidents and accidents and the processes involved are better understood and measured for the different types of cargo, stages of shipment and levels of impacts. ${ }^{16}$

Most behavioral studies assist in the assessment of collision candidates that provide a useful method of collision risk assessment in complex transportation systems and the effect of safety measures in the context of Formal Safety Assessment studies as defined by the IMO in $2007 .{ }^{23}$ Collision candidates are ships in a near collision situation, which was defined using the concept of vessel domain introduced by Fujii and Tanaka ${ }^{24}$ and Goodwin ${ }^{25}$ and subsequently improved by several authors. ${ }^{26-30}$
Real-time anomaly detection can identify potential safety hazards in navigation and therefore is valuable for an intelligent navigation system on board vessels and for port and related authorities. This procedure indicates typical patterns of movement of historical data and identifies suspicious vessels that deviate significantly from common movement patterns. ${ }^{31}$

While the normal movement of the ship is largely predictable, since it generally follows a pattern, the irregular motion characteristics of anomalous ships are less predictable. These ships are at higher risk of collision, particularly in areas of high traffic density, such as busy ports and congested traffic lanes. ${ }^{18}$ Of the 435 events registered in the Brazilian waters in 2009, $110(25.2 \%)$ were from the wreck category (North region 26-23\%), 69 from the collision category $(15.9 \%)$ Northern region $12-17 \%$ and $23(5.8 \%)$ were of the fire category. ${ }^{32}$

The estuarine areas of the Amazon Basin under Brazilian jurisdiction that connect the ports of the Amazon River and its tributaries and the rest of the planet are crossed by commercial routes of the merchant navigation. Here ships embark to the national and international ports, through merchant shipping vessels (Bulks, Tankers, Containers Ships), and fishing vessels, pleasure craft, in traffic from South America to North America, Africa, Europe, Asia and Oceania creating a complex network of routes. This paper discusses these threats, the challenges to address them, the relevant regulatory and non-regulatory tools, and the next steps to reduce risk from the appropriate methodology for the Amazon region.

In addition to the large hydrographic basin, the Amazon biome is home to the largest existing tropical forest, the largest genetic bank on the planet and a major mineral heritage. It is an ecosystem of inestimable importance for the planet, being also a great sink of carbon, contributing to the global balance. ${ }^{33}$ There are considerable environmental risks represented by the exchange of Ballast Water in the Ports of the Legal Amazon, based on the number of vessels - annual average of 2648 records $^{20}$ and their respective volumes exchanged locally throughout the year, both associated to the precarious sanitary conditions of the coastal zone close to the ballast water exchange operations. ${ }^{3,34}$

In relation to the Legal Amazon, the increase in commercial transactions with other countries in the world, which in the last ten years had their values for exports increased by almost $100 \%$, represents a consequent increase in the threats to Ballast Water and other sources from merchant shipping operations. ${ }^{35}$

The loading on the Amazon Basin Waterways indicates a vocation for the transportation of three main groups of products: general cargo, solid bulk (iron ore, non-ferrous metal and non-ferrous minerals) and solid agricultural bulk (with soybean and forest products and forestry). The loading is not uniform, with each waterway carrying different types of products. ${ }^{33}$

The busiest product in the area of the Waterways of the Amazon Basin was iron ore, which obtained more than $70 \%$ of the total participation in 2010, exporting more than 99 million tons. Table 1 summarizes the main products handled in the waterways in 2010 and their respective projections for the period 2011-2030.

Table I Load Handling Projection - Amazon Basin - 2010-2030.

\begin{tabular}{llllll}
\hline Import Products & $\mathbf{2 0 1 0}$ & $\mathbf{2 0 1 5}$ & $\mathbf{2 0 2 0}$ & $\mathbf{2 0 2 5}$ & $\mathbf{2 0 3 0}$ \\
\hline Fertilizers ( $\mathrm{t})$ & 1.037 .011 & 1.356 .739 & 2.022 .496 & 2.359 .806 & 2.467 .127 \\
Iron Derivatives $(\mathrm{t})$ & 402.433 & 414.280 & 369.247 & 323.092 & 258.647
\end{tabular}


Table Continued....

\begin{tabular}{|c|c|c|c|c|c|}
\hline Import Products & 2010 & 2015 & 2020 & 2025 & 2030 \\
\hline Oil derivates $(\mathrm{t})$ & 5.106 .602 & 6.206 .615 & 6.292 .155 & 6.401 .543 & 6.394 .701 \\
\hline Electric materials $(\mathrm{t})$ & 288.254 & |52.87| & III.772 & 103.975 & 83.103 \\
\hline Ores, Metals, Metallurgical Products and Precious Stones ( $\mathrm{t}$ ) & 3.019 .908 & 1.989 .429 & 2.905 .243 & 4.309 .965 & 5.631 .491 \\
\hline Product of Chemical Industries ( $\mathrm{t}$ ) & 2.228 .836 & 2.828 .637 & 2.868 .229 & 3.298 .467 & 3.460 .332 \\
\hline Wheat $(\mathrm{t})$ & $269.883,06$ & $449.121,46$ & $475.304,05$ & $475.377,64$ & $475.378,00$ \\
\hline Total Imports & $12.352 .925,73$ & |3.397.693, 18 & $15.044 .445,53$ & I7.272.226,42 & | 8.770.777,53 \\
\hline Export Products & 2010 & 2015 & 2020 & 2025 & 2030 \\
\hline Pig iron $(t)$ & I.479.204 & 3.571 .196 & 6.141 .463 & 7.518 .396 & 8.275 .547 \\
\hline Iron ore (t) & 99.136 .965 & $\mid 36.807 .813$ & I89.482.442 & 209.572 .130 & 225.485 .607 \\
\hline Ores, Metals, Metallurgical Products and Precious Stones ( $\mathrm{t}$ ) & 11.973 .625 & 8.260 .468 & 8.549 .956 & 8.578 .652 & 8.665 .351 \\
\hline Product of Chemical Industries $(t)$ & 6.577 .105 & 7.517 .555 & 9.501 .496 & II.087.224 & 12.650 .238 \\
\hline Soy $(t)$ & 7.508 .799 & II.225.258 & |4.058.986 & I5.969.254 & 17.638.952 \\
\hline Total Exports & I 26.675.698 & 167.382 .289 & 227.734 .343 & 252.725 .657 & 272.715 .695 \\
\hline Total (t) & 139.028 .623 & | 80.779.982 & 242.778.789 & 269.997 .884 & 291.496 .473 \\
\hline
\end{tabular}

The results presented in the Amazon Basin Technical Report as seen in the table above indicate, for 2010 and for the adjusted years, the absolute predominance of iron exports, increases in soybeans, chemical products and pig iron. Among the import products, one can notice a greater significance of petroleum and metallurgical products and a strong expansion in the demand of fertilizers and fertilizers. ${ }^{33}$

To ensure the safety of navigation and improve navigation efficiency, the traffic flow of ships was surveyed and analyzed based on Automatic Identification System (AIS) data provided by Marine Traffic to improve traffic management and improve the safety of aquatic traffic in the region. ${ }^{36-38}$

Behavior of the ship refers to its position, speed, direction, distance and time between any two neighboring ships and other ships moving or standing in the region under study. The behavioral characteristics refer mainly to the change of behavior of the ships during the movement and, therefore, they vary in different points in the space and the time. The behavioral characteristics include vessel position, speed, direction, distance, time between vessels and distribution and the values representative of these factors. ${ }^{38,39}$

The present study used data from vessel traffic of the Marine Traffic Automatic Identification System (AIS) for the period of March 16, 2016 and March 16, 2019, and covered all vessels that passed through the Ship Monitoring Area (AMN) to the Amazonian ports, and in the reverse direction on the way out to the Atlantic Ocean (Figure 1).

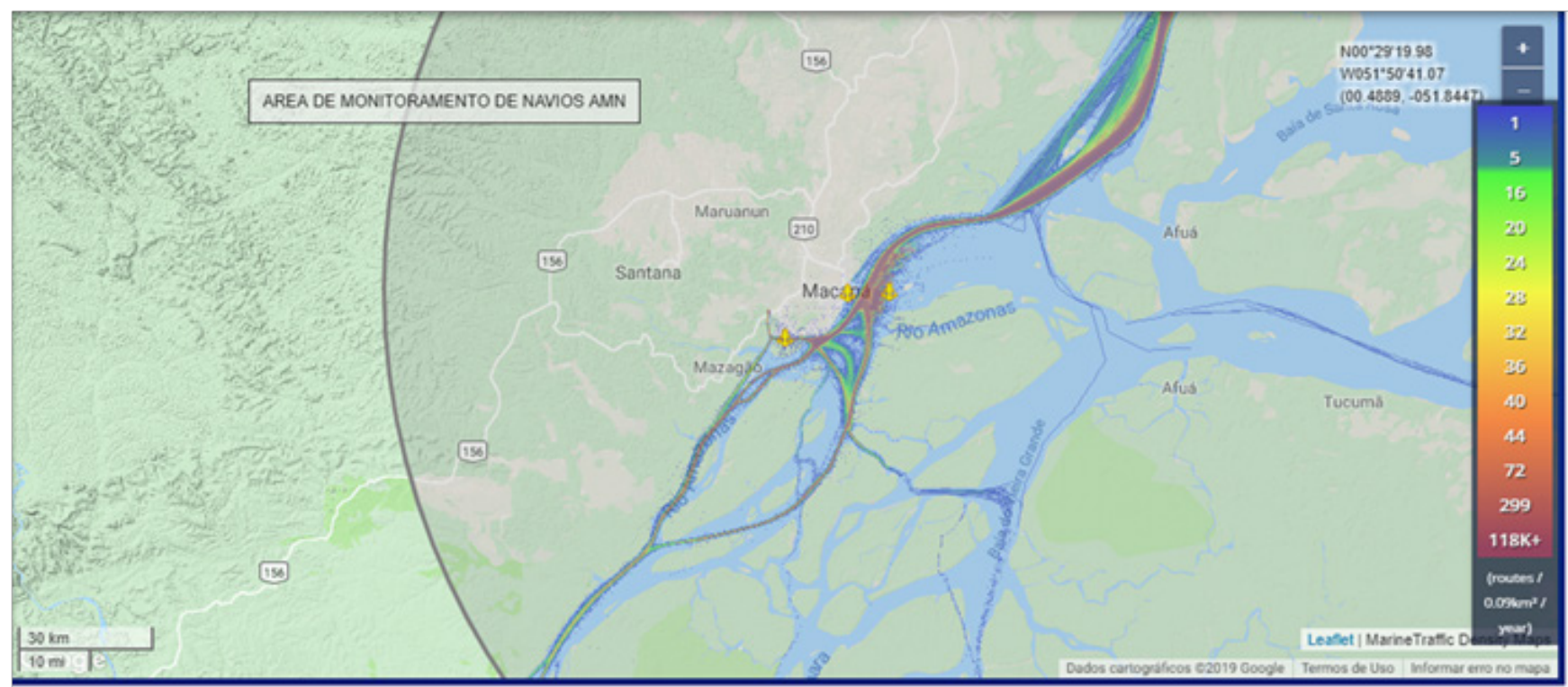

Figure I Density of vessel traffic in the AMN. 
The deficiency in the quality and frequency of the AIS signal for the identification of merchant ships in Amazonia shows the need to install AIS devices in the region to ensure the safety of navigation with a VTS equipped with several (AIS) capable of receiving and maintaining message records transmitted by AIS transceivers from ships, as another tool to avoid collisions and other incidents. ${ }^{40,41}$

The methodology proposed in this document begins with the analysis of the AIS data collected during the research period. The correlation between each ship property and the behavioral factor is calculated based on the AIS data. The property of the ship with strong correlation with the behavioral factor can be used as a criterion to group the corresponding behavioral factor through tests of significance. The behavior with significant differences is grouped. Finally, the limits of each classification criterion are determined by the behavior clusters.

The results of the revealed behavior analysis explain that vessel behavior varies mainly when some vessel property differs, but vessels of the same group do not exhibit behavior in a similar pattern. Thus, this article is inspired by the tendency of variation of the behavior with the change of the property of the boat. The results of the classification of the vessel based on its behavior can lead to a greater consistency for future analyzes, simulations and predictions of the behavior of the ships, based on the systematic recognition of the behavior patterns of the ships already studied.

The analysis of ship traffic in the Amazon is essential to understand the current operations and future trends of growth and changes in the region's economy, and global. The aquatic traffic in this region was characterized and a statistical analysis was carried out that determined the patterns of boat behavior in general and by category separately.
This article is organized as follows. Section 2 describes the method and previous related studies. Section 3 provides the actual ship navigation situation in the AMN on the basis of statistical analyzes and vessel trajectory. Section 4 presents the discussions and interpretations of the results and the conclusions of this study with some recommendations directed to those involved in the theme in the region.

\section{Materials and methods}

This methodology has been implemented, as water transport is an important activity throughout human history, especially when progress depends mainly on international trade, and can be considered as one of the four pillars of globalization, along with communications, international standardization and trade liberalization. ${ }^{4}$

The relationship between the ship's behavior and the waterway transport capacity was investigated, and with these results can be developed models of water transport capacity based on the behavior and the profile of the ships. ${ }^{42}$ The characteristics of vessel flow behavior were also studied and analyzed together with the behavioral information of the vessels. ${ }^{7,43}$

The study area selected for these traffic and collision risk studies was called the Ship Monitoring Area - AMN (Figure 2), and the main reason for choosing this area was the geographical importance of the mandatory entry and exit route of the vessels that carry out merchandise trade in the Amazon. A second reason is the importance of this monitoring for the conservation of Amazonian biodiversity and protection against catastrophic events involving these vessels.

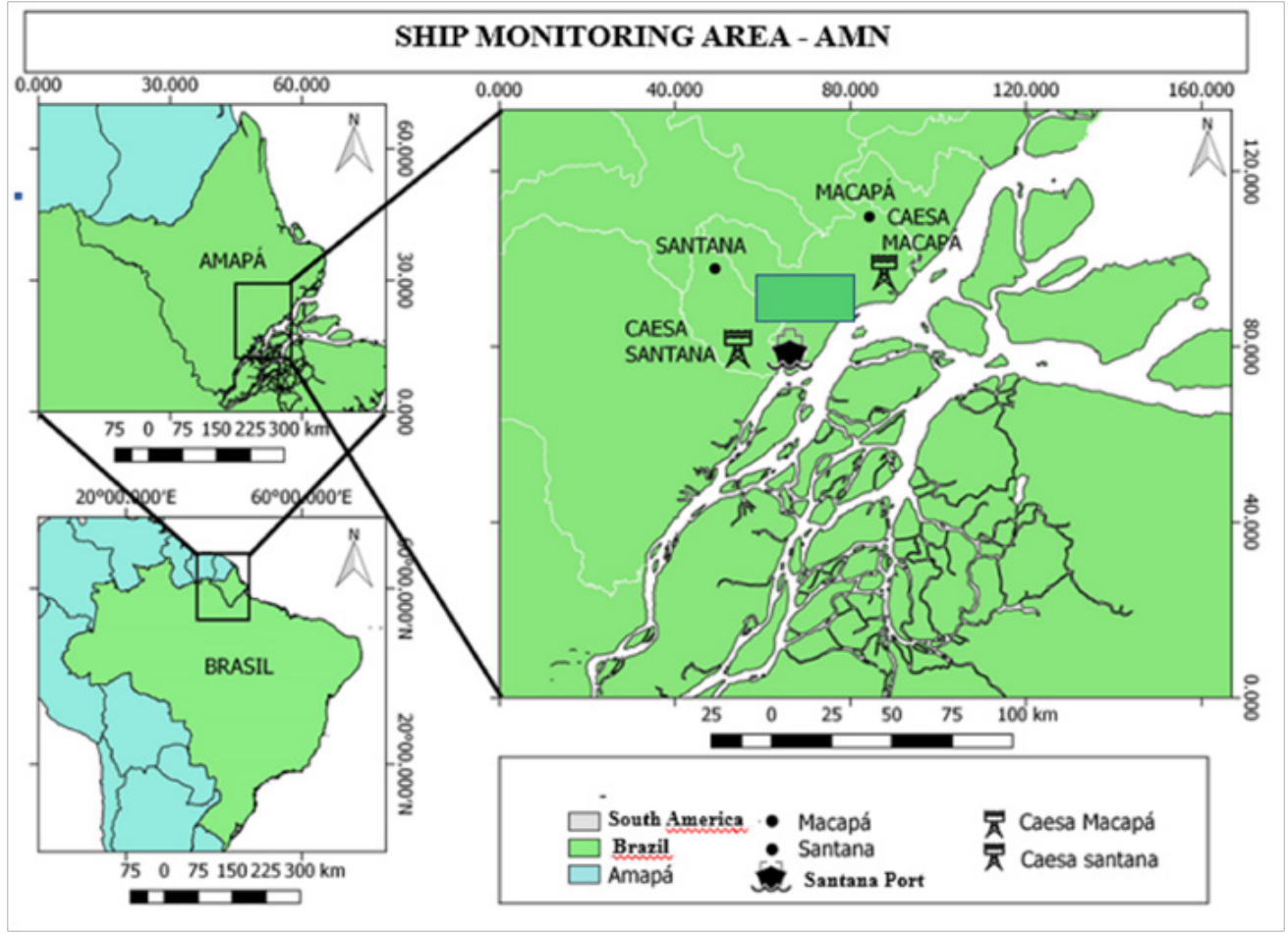

Figure 2 Ship Monitoring Area - AMN.

The vessel traffic flow is closely related to the safety and efficiency of navigation, as well as the practical planning of ports, and has received considerable attention in the maritime traffic engineering research field. ${ }^{43}$ According to information found on the Agency of
Waterway Transportation website, only in 2012 circulated by the Amazonian waters in 1358 vessels made their entrance by the Amazon River waters, and of these, 1266 (93\%) were ships that carried cargo transportation. ${ }^{35}$ 
The environmental conditions of vulnerability of coastal ecosystems of the Lower Amazon River and its tributaries that drain urban areas, industrial and/or port, represent a potential set of risks to public health and can promote favorable conditions for Bioinvasion of alien species, raising the level of environmental risk in these impacted areas. $^{34,44}$

The importance of studies on pollution from merchant shipping and the management of ballast water in port areas of the Amazon becomes extremely necessary because the supply of water contamination risks have favorable conditions and any pollutant releases, may result in public health problems, as well as possible disturbances to Amazonian aquatic ecosystems. ${ }^{44,45}$

The search period where AIS data for ships were recorded from 16 March 2016 to 16 March 2019 for all vessels entering or leaving the
AMN. The data recorded consist of the name, International Maritime Organization (IMO) number, nationality, flag, date and time of arrival, length, width, knots speed and geographical positioning (GPS).

Identification of ships and data entered in the vessel movement database were obtained from the Marine Traffic website (Figure 3) by positioning the satellite in the desired area, instantly identified ships appear. The site adopts the classification of colors for the different types of vessels (CARGO-green, TANKERS-red, PASSENGERSdark blue, TUG-light blue, FISHING-orange and PLEASUREpurple). On the left side of the map are the command buttons like filters, layers, my fleet, playback and density maps. Vessels also vary in size on the icon according to their actual dimensions and appear in the direction of the route in which they are navigating. When stopped, they are represented by a point of the respective color.

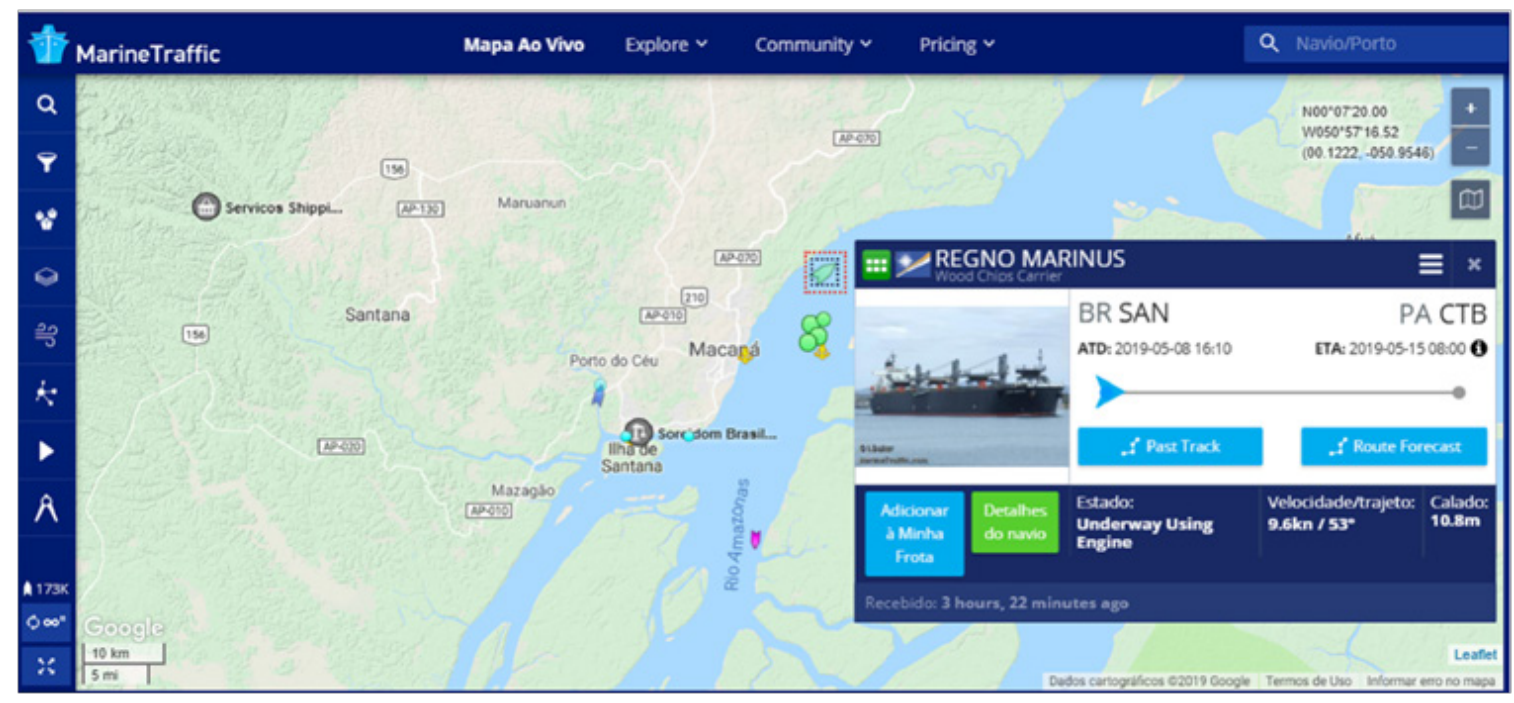

Figure 3 Marine Traffic - panorama study area.

When selecting one of the boats, a summary of your information such as Type, Name, Flag, Port of Origin, Port Destination, departure and arrival times, boat status, speed (in) and draft (m) will appear.
If "Ship Details" is selected, a new screen appears with all vessel management and behavior information (Figure 4).

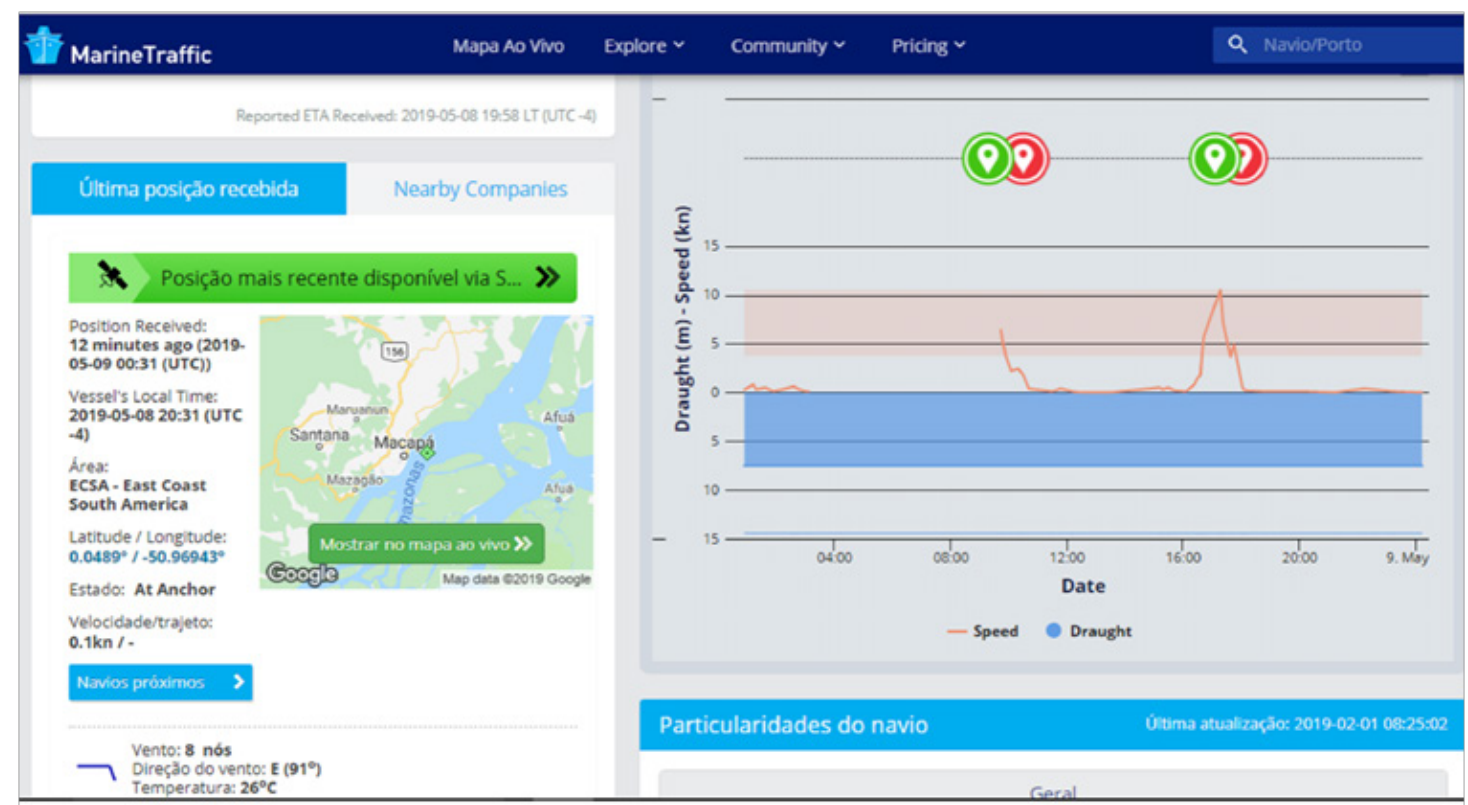

Figure 4 Marine Traffic - Vessel Details.

Citation: Pereira JPFN, Pereira NN, Cunha AC. Use of Automatic Identification System (AIS) data to study patterns of navigation behavior in the Macapá and Santana / AP / Brazil Ship Monitoring Area (AMN). J Aquac Mar Biol. 2019;8(3):95-104. DOI: 10.15406/jamb.2019.08.00247 
In this new page, details such as the geographical position (latitude/longitude), weather characteristics (wind, wind direction and ambient temperature), boat speed graph, and information receiving data (AIS station and transmission time of the data). By selecting the "next ships" option, a new page opens (Figure 5).

\begin{tabular}{|c|c|c|c|c|c|c|}
\hline MarineTraffic & & pa Ao Vivo & Community & Pricing ${ }^{\vee}$ & & Q NavionPorto \\
\hline \multicolumn{7}{|c|}{$\begin{array}{l}\text { Discover all vessels salling near the CLOVER vessel } \\
\text { view Detalhes do navio }\end{array}$} \\
\hline \multicolumn{2}{|c|}{ All Vessels } & \multicolumn{2}{|c|}{ Ao alcance } & My fleets & \multicolumn{2}{|c|}{ Ao meu redor } \\
\hline Nome do navio & Volocidade (kn) & Trajoto (") & Porto atual & Distaincia ató... (NM) & Rumo (") & Interseçäjo de rotas em.. \\
\hline CLOVER & 14.1 & 56 & & 0 & 0 & \\
\hline $\begin{array}{l}\text { BAP MEDLANA } \\
\bar{\nu}\end{array}$ & 7.2 & 216 & & 1.13 & 41 & $\begin{array}{l}-1 \text { minutes ( }(0.31 \text { n.miles) } \\
\text { Possible collision }\end{array}$ \\
\hline $\begin{array}{l}\text { STEMWINDER } \\
e\end{array}$ & 3.1 & 271 & & 2.58 & 9 & \\
\hline $\begin{array}{l}\text { LUTETIA } \\
\odot\end{array}$ & 0.1 & 0 & MACADA BAY ANCH & 2.79 & 38 & \\
\hline EM COMTE SILVANO & 8.5 & 274 & & 2.88 & 27 & \\
\hline NM ANA BEATRIZ III & 13.4 & 133 & SANTANA & 3.09 & 322 & $\begin{array}{l}0 \text { minutes (0.47 nmiles) } \\
\text { Possible collision }\end{array}$ \\
\hline
\end{tabular}

Figure 5 Marine Traffic - Nearby Ships.

In this page in the left column appears in the first position the ship in detail, below the others consequently by proximity. Important information such as speed, path, port, distance between vessels, heading and intersection points are present, which indicates the domain intrusion events automatically detected by the artificial intelligence of the site performing calculations of collision risks. When one of these registers exists (passing hazards from the front, dangerous passage from behind and possibility of collision), the option can be selected, and a new page opens (Figure 6).

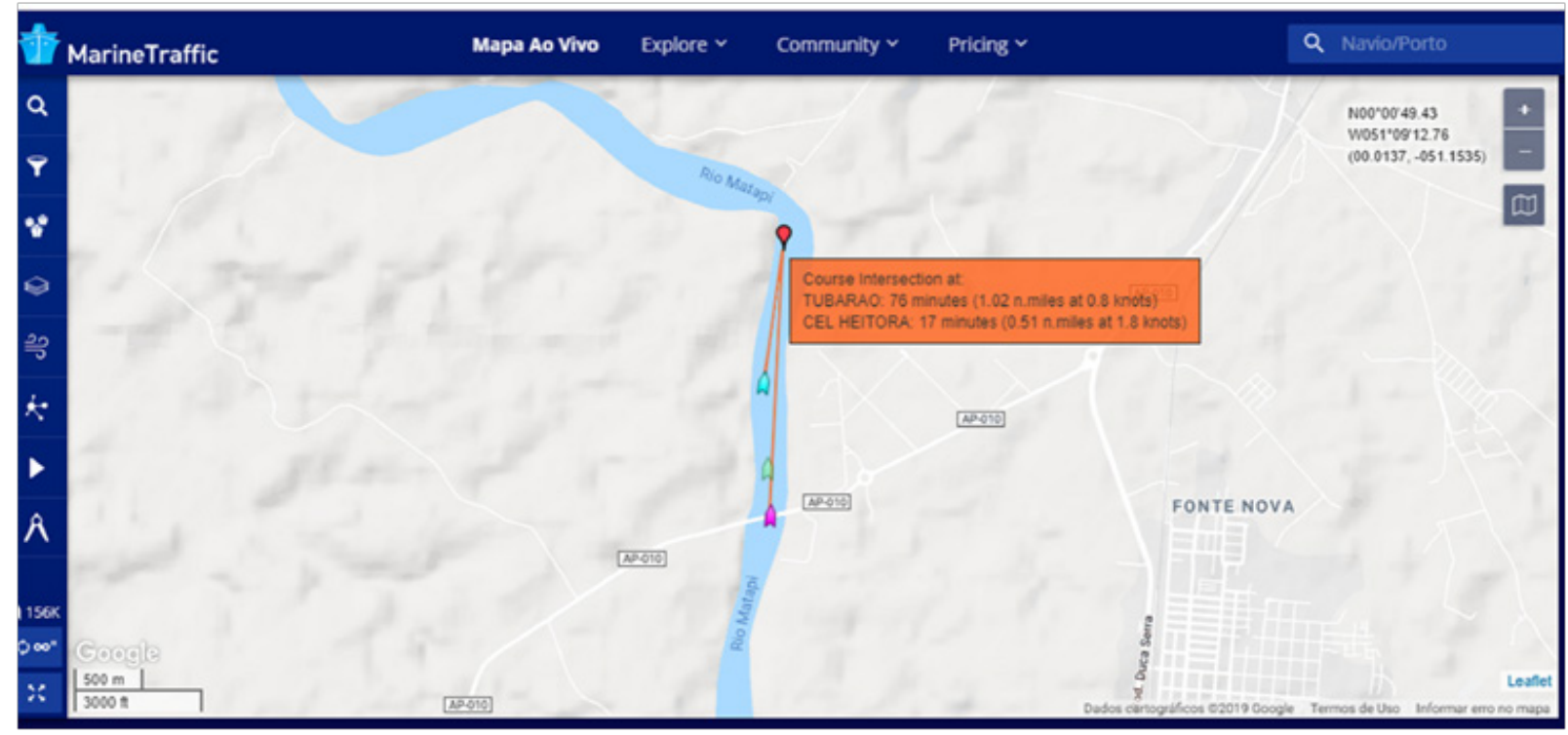

Figure 6 Marine Traffic - Event Details.

This image shows the vessels involved in the record, with details for each boat such as the time to the event, distance to travel (nautical miles) and speed (nos) at the time of the event.

The statistical significance test was performed for data from the authors' AMN Database 2016-2019 using the R Project data analysis tool. In this study, the value of $\mathrm{p}<0.05$ was taken as the criterion to decide level of significance. When there was no significant difference between these two sets of data, the behavior was considered to be in the same pattern. These two sets of data were pooled to be tested with the next subset. When there was a significant difference between these two datasets, the vessels in these two sets were classified into different groups. Therefore, the previous cluster of this specific behavior is finished. The last subset of data was tested with the next subset. 


\section{Results-Analysis of AIS Data-Monitoring $20 \mid$ | -20| 7-20| 8}

By examining the AIS data, the volume of vessel traffic was obtained for this period. The graph in Figure 7 shows the results of the number of vessel movement records. The records of Ships (REGNAV) according to the month of registration (MESREG) for the three years of monitoring in the AMN (YEAR I -14/03/2016-13/03/2017 YEAR II 14/03/2017-13/03/2018 YEAR III 14/03/2013-13/03/2019).

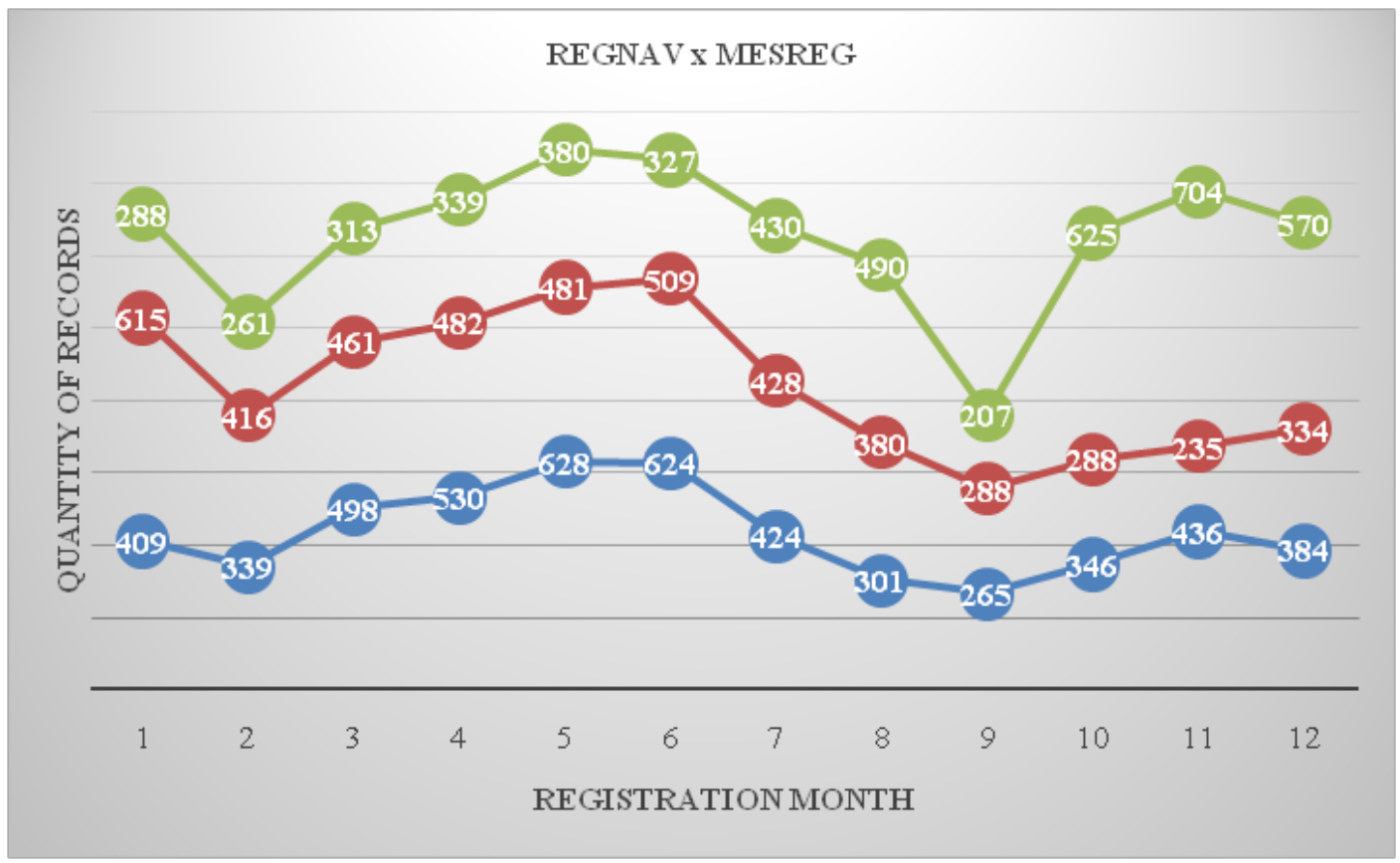

Figure 7 Behavior of Ships - Record of Movement - AMN 2016-2019.

We verified from the IMO / MMSI record number 15035 ship records passing during the period of the survey, with an average value of 417 records and a maximum value of 704 records for month 11 of year III. The chart shows that the number of vessels exhibits behavioral patterns of movement drop for months 02 and 09 , and growth behavior in the periods between 03 and 06 , and in the period of months 09 and 12. Due to failures in AIS, we can observe a fall in the records of the month 09 of year III.

As a result of monitoring for type of ships (Figure 8), we obtained results based on IMO / MMSI numbers records where $69 \%$ of all ships passing in the area were cargo type (Bulk Carrier, Container Ship, General Cargo, Cabu Carrier, Cement Carrier and Ore Carrier). The second most registered type Tanker (Chemical Tanker, LPG Tanker, Oil Products Tanker and Oil / Chemical Tanker) presented 13\% of the Amazonian fleet. Passenger ships with $8 \%$ of records (Transatlantic and regional navigation) in the Amazon region are behind in records of auxiliary ships, others and unidentified.

We found that most of the vessels operating in AMN belong to the CARGO type, particularly Bulk Carriers and Containers Ships following patterns of behavior similar to that of the $59 \%$ world fleet. ${ }^{21}$ The total percentage of TANKERS-type vessels (13\%) represents the share of oil and gas transport, corresponding to that of the world fleet, specifically those of the LGP Tankers type, which had a fleet increase of $7 \%$ and a total value of 29.2 per cent. $^{21}$

It is also worth pointing out the number of passenger ships, especially the transatlantic ones that also increased their activities in the AMN. Class B vessels, including auxiliary, military and unknown vessels represent a considerable amount $(10 \%)$, indicating a pattern of behavior peculiar to the region and indicating the need for special attention to the operations of these vessels and their behavior in Amazonian roads.

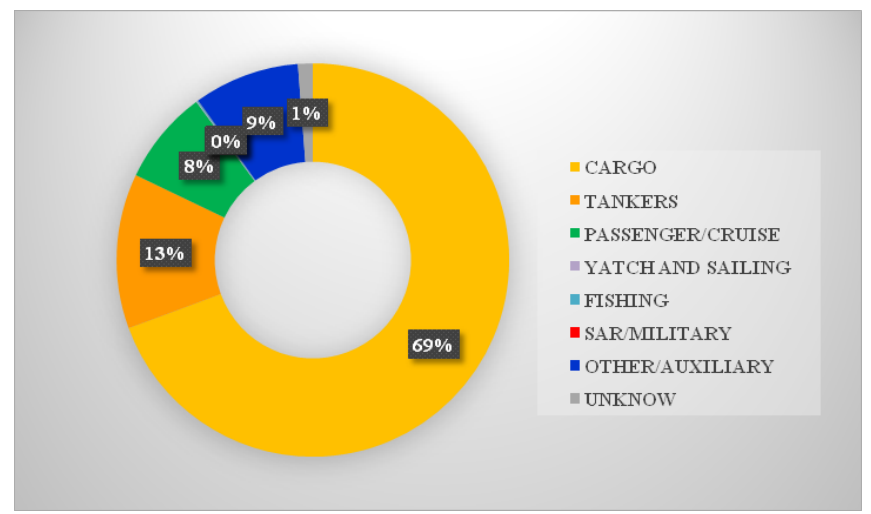

Figure 8 Ship Behavior- Type of Ship - AMN 2016-2019.

Figure 9 shows the monthly average speed records (knots) of the ships that traveled in the AMN during the monitored period. According to the Brazilian Navy's Navigational Standards Manual for the Macapa and Santana Region, the maximum speed for 5 (05) in the three-year curves is evident that the Amazon fleet is traveling above the speed limit. The values are between double and triple the limit value, implying in the urgent need of revisions in the norms and laws that regulate such actions.

Another behavioral characteristic analyzed was the Ship Registration Flag. This analysis generally leads the researchers to conclude that the analyzed fleet presents the classic Flagship values of "convenience" (Panama, Marshal Islands and Liberia), as can be observed in Figure 10. 


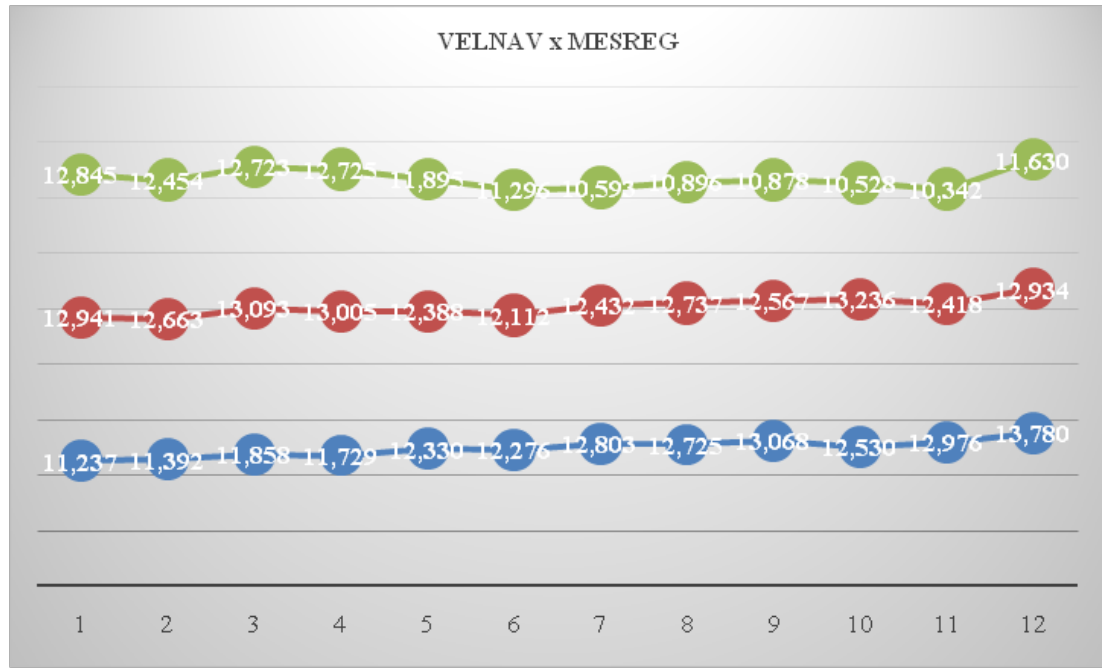

Figure 9 Ship Behavior- Speed - AMN 2016-2019.

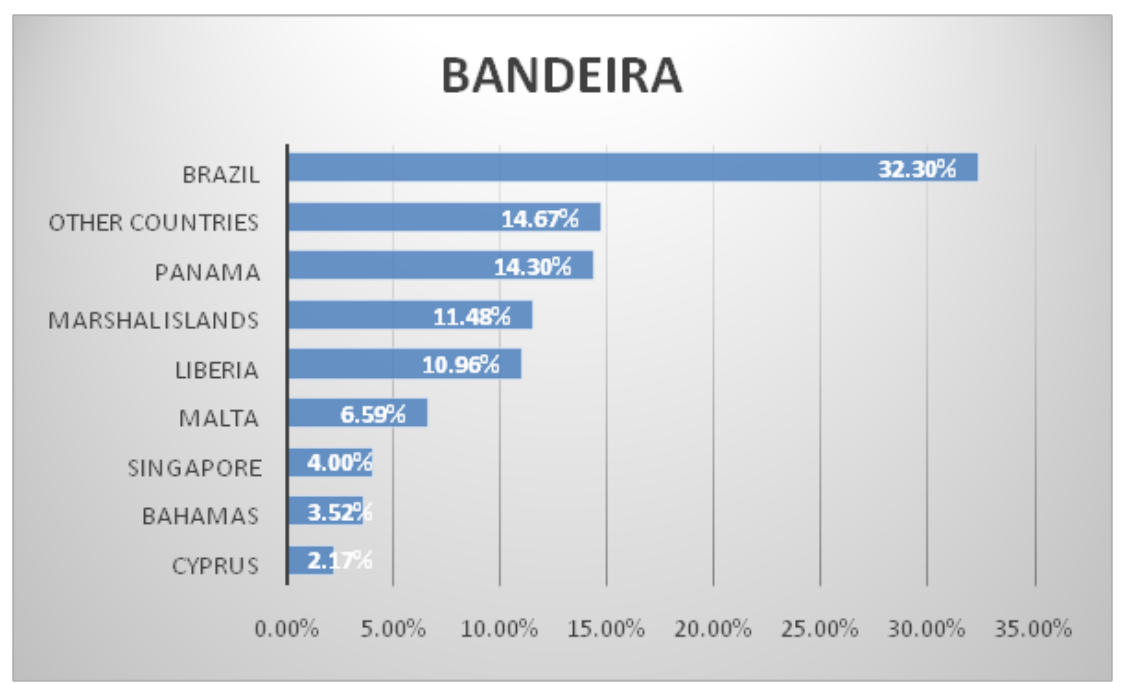

Figure 10 Ship Behavior - Flag - AMN 2016-2019.

But in the Amazonian reality we can see a predominance of ships with Brazilian flag, which can be favorable when new laws and standards are adopted. Ships of Brazilian flag stayed with 32,3\%, whereas the classic countries presented registries of Panama 14,3\%, Marshal Islands 11,5\% and Liberia 10,9\%.

Regarding the year of manufacture, the ships monitored in the period presented boats manufactured between 1948 and 2018, with a growing average age showing that the fleet operating in the region is being renewed in a similar way to the growth of the world fleet. Characteristics as the dimensions of the ships presented for length maximum value of $294 \mathrm{~m}$, minimum speed of $10 \mathrm{~m}$; for width maximum value of $52 \mathrm{~m}$, minimum love of $03 \mathrm{~m}$.

The Port of Origin is an important characteristic to be analyzed in the behavior of ships, since it indicates the origin of the ballast water contained in the ballast tanks in the ship, and consequently the origin of the living species present that can become potential invaders. In this analysis we find records of approximately $70 \%$ for national ports (cabotage navigation), reducing the risk of invasions of species from other regions of the planet, but increasing the possibilities of Bioinvasion of species of the country and Amazonian region.
Porto Destino (Destiny Port), another analyzed behavioral factor, can also be used by regional and national organizations to study economic performance in relation to the import and export negotiations represented by the merchant shipping business. Ships leaving the Amazon basin, with exporting trends in commodities (minerals, wood, petroleum products), have a predominant destination for Brazilian ports $(75 \%)$, with special emphasis on the ports of distribution of commodities such as the port of Alumar (MA ) with $7 \%$ of destinations.

Several management and navigation solutions could be implemented at AMN as a matter of urgency to improve the safety of on-site navigation, such as a Traffic Separation Scheme (TSS). According to TSS, opposing traffic flows are separated by the establishment of traffic lanes.

However, these risk reduction solutions mentioned above are usually based on the qualitative and subjective judgment of specialists. There is no study to quantitatively assess the risk of collision of ships in this particular region of the international aquatic trade. Hence the importance of proposing a procedure to quantitatively assess the risk of collision in the AMN to support these expert evaluations. ${ }^{19}$ 
The AIS signal at AMN was out of air in 90 days $(8.20 \%)$ of the 1095 monitored days. In those days it was not possible to carry out the monitoring because the information of the ships in the region are unavailable and can be justified by problems in the sources of communication like cell towers and satellite signals.

\section{Conclusion}

A vessel behavior monitoring model is a powerful tool to facilitate the processing of aquatic data and to promote aquatic intelligence. The precise recognition and description of the elements and their dynamic relationships in a maritime transport system provide a solid platform for users to understand the causality of ship behavior from massive data and reduce the risk of ship collision. ${ }^{18}$

The monitoring of ships in the AMN, the characterization of the Amazon fleet, and environmental impact studies, for the populations of the region, and consequently the economy, demonstrate the importance of maritime safety, which is governed by the combination of international rules and regulations, regulations national flag states and port states, port regulations, classification societies rules and insurance companies. ${ }^{21}$

The hostile scenario, especially in the aquatic environments, poses many challenges not only to ship operators, but also to those responsible for safety management. ${ }^{39}$ The organizations involved must be prepared to be able to maintain sufficient security control and make plans to overcome the risks, that is, be prepared for all foreseeable situations that may be encountered and which may cause harm to the economy, society and the environment, and therefore the knowledge of the fleet profile and its behavior in the operations carried out in the study area facilitates safety control and risk studies in these operation. ${ }^{17}$

To properly manage security, everyone involved needs important information to support the decision-making process. Sufficient information is needed to identify the problems (if any) in time and to plan, give orders and allocate assumptions to perform the necessary actions. An efficient security management system provides sufficient support for operators to be aware of the state and variations of safety margins. ${ }^{31}$

This article presents the behavioral analysis of vessels in the area of ship monitoring - AMN, Macapa and Santana, from the perspective of the behavior of ships that sailed between 2016 and 2019, including the type of vessel, number of records, flag, year of manufacture, port of origin, port of destination, geographic location, date, time and speed.

The results of these analyzes can help related competent authorities and other stakeholders in route optimization and water management projects, and for researchers, provide a systematic way to understand, simulate, and predict behaviors.

When plotting the AIS data along with the statistical studies, behavioral patterns, correlations between vessel behavior and its different properties were observed and that each behavioral factor is grouped according to the correlated properties of the vessels. As a form of continuous protection, we suggest some actions aimed at the preservation, conservation and development of Amazonian biodiversity, to control and mitigate these presented risks inherent in merchant shipping operations.

For future research, the behavior of ships in their arrival and departure displacements of the Amazonian ports should be analyzed and monitored constantly to describe the entire shipping route, the areas of this waterway and the imminent risks of these operations.

Due to the signal faults presented, it is recommended the immediate installation of an AIS unit in the region, thus ensuring greater coverage of ship handling, thus increasing safety in the area.

\section{Acknowledgments}

Thanks to the Laboratory of Chemistry, Sanitation and Modeling of Environmental Systems (LQSMSA) and the support from the Brazilian Council of Scientific and Technological Development (CNPq, grant \# 309684/2018-8).

\section{Conflicts of interest}

The author declares that there are no conflicts of interest.

\section{References}

1. Kaluza P, Kolzsch A, Gastner MT, et al. The complex network of global cargo ship movements. J R Soc Interface. 2010;7(48):1093-1103.

2. Butt N, Johnson D, Pike K, et al. 15 Years of Shipping Accidents: A review for $W W F$. Southampton Solent University. Project Report. Southampton. 2013.

3. Pereira JPFN. Monitoring of ballast water in the port area of Santana/ AP: support for public management policies. Master's Dissertation of PPGDAPP/UNIFAP. 2013;122 p.

4. Helen S, Bloor M, Baker S, et al. Greener shipping? A consideration of the issues associated with the introduction of emission control areas. Policy Manag. 2016; 43(3):295-308.

5. UNCTAD - United Nations Conference on Trade and Development. Review of Maritime Transport. 2009.

6. OECD-Organization for Economic Co-operation and Development. Cost Savings Stemming from Non-Compliance with International Environmental Regulations in the Maritime Sector. 2003.

7. Liu Z, JX Liu, YX Liu, et al. Model of prediction and statistics on time pattern of traffic flow. Proceedings of the 2nd International Conference on Transportation Information and Safety, Wuhan. 2013;2341-2350.

8. Xiao FL, L Han, VG Coen, et al. Comparison study on AIS data of ship traffic behavior. Ocean Engineering. 2015;95:84-93.

9. IMO-International Maritime Organization. MSC Circ.1023 / MEPC 392, Guidelines for formal safety assessment (fsa) for use in the imo rule-making process. 2002.

10. IMO-International Maritime Organization. Automatic Identification Systems (AIS). 2016; Access May 14, 2018.

11. Onwuegbuchunam DE, Ebe TE, Okoroji LI, et al. An Analysis of ShipSource Marine Pollution in Nigeria Seaports. Journal of Marine Science and Engineering. 2017;5(3):39.

12. Hu S, Zhang J, et al, Risk assessment of marine traffic safety in coastal water area. Proceedings Eng. 2012;43:31-37.

13. Eide MS, Endresen O, Brude OW, et al. Prevention of oil spill from modeling of dynamic risk. Marine Pollution Bulletin. 2007;54: 1619 1633.

14. Goerlandt F, Kujala P. Traffic Simulation Based Ship Collision Probability Modeling. Reliability Engineering and System Safety. 2010;96:91-107.

15. Hassel M, Utne IB, Vinnem JE. Analysis of the main challenges with the current risk model for collisions between ships and offshore installations on the Norwegian Continental Shelf. In: 12th International Probabilistic Safety Assessment and Management Conference, PSAM. 2014. 
16. Li S, Meng Q, Qu X. An Overview of Maritime Waterway Quantitative Risk Assessment Models. Risk Anal. 32(3):496-512. 2012.

17. Last P, Bahlke C, Hering-Bertram M, et al. Comprehensive analysis of automatic identification system (ais) dates in regard to vessel movement prediction. Journal of Navigation. 2014;67(5):791-809.

18. Tu E, Zhang GH, Rachmawati L. Exploiting AIS data for intelligent maritime navigation: a comprehensive survey from data to methodology. IEEE Trans Intell Transp Syst. 2016;19(5):1-24.

19. Pereira JPFN, Pereira NN, Cunha AC. Monitoring of Ballast Water Quality as a support to Management in the Port of Santana-AP Estuarine Amazon / Brazil (in Portuguese). Ballast Water: Management and Control. In: NN Pereira. Blucher. 2018:171-198.

20. Pereira NN, Botter RC, Folena RD, et al. Ballast water: a threat to the Amazon Basin. Marine Pollution Bulletin. 2014

21. UNCTAD-United Nations Conference on Trade and Development Review of Maritime Transport. 2018.

22. Hu S, Fang Q, Xia H, et al. Formal safety assessment based on relative risks model in ship navigation. Reliability Engineering and System Safety. 2007;92(3):369-377.

23. Martins M R, Maturana MC. Human Error Contribution in Collision and Grounding of Oil Tankers. Risk Analysis. 2010;30(4):674-698.

24. Fujii Y, Tanaka K. Traffic capacity. Journal of Navigation. 1971;24(4):543-552.

25. Goodwin EM. A statistical study of ship domains. Journal of Navigation. $1975 ; 28(3): 328-344$.

26. Coldwell T. Marine Traffic Behavior in Restricted Waters. Journal of Navigation.1983;36(3):431-444.

27. Zhao J, Wu Z, Wang F. Comments on ship domains. Journal of Navigation. 1993;46(3):422-436.

28. Pedersen PT. Collision and Grounding Mechanics. The Danish Society of Naval Architects and Marine Engineers. 1995;125-57.

29. Pietrzykowski Z. Ship's Fuzzy Domain - the Criterion for Navigational Safety in Narrow Fairways. Journal of Navigation. 2008; 61(3):499-514

30. Pietrzykowski Z, Uriasz J. The ship domain - a criterion of navigational safety assessment in an open sea area. Journal of Navigation. 2009; 62(1):93-108.
31. Heij C, Knapp S, Henderson R, et al. Ship incident risk around the heritage areas of Tubbataha and Banc d'Arguin. Transportation Research Part D. 2013;25:77-83.

32. Marinha Do Brasil (Brazil's Navy). Maritime Court. 2009

33. ANTAQ - National Aqua Transportation Agency; Laboratory of Transport And Logistics (LABTRANS / UFSC). (2013).

34. Cunha AC, Pinheiro LAR, Cunha HFA, et al. Simulation of Hydrodynamics and Dispersion of Pollutants with Virtual Monitoring in the Matapi River - AP. Journal of Environmental Studies-REA. 2011;13:2:18-32.

35. ANTAQ-National Aqua Transport Agency. The Development of Cabotage Navigation in Brazil. 6th Logistics and Transport Meeting, FIESP, on 06/14/11. Lecture by Wagner de Souza Moreira. 2011

36. Zhang LD. The study of vessel traffic flow in Chengshantou waters based on AIS data. Master's thesis, Dalian Maritime University. 2010.

37. Aydogdu YVC. Yurtoren JS, Park YS, et al. A study on local traffic management to improve marine traffic safety in the Istanbul Strait. Journal of Navigation. 2012;65:99-112.

38. Chou C, Su Y, Li R, et al. Key navigation safety factors in Taiwanese harbors and surrounding waters. Journal of Marine Science and Technology. 2015;23(5):685-693.

39. Wen YQ, YM Huang, $\mathrm{CH}$ Zhou, et al. Modeling of marine traffic flow complexity. Ocean Engineering. 2015;104,500-510.

40. Graveson A. AIS-An Inexact Science. Journal of Navigation. 2004;57(3):339-343

41. Norris A. AIS implementation - success or failure. Journal of Navigation. 2007;60:373-389.

42. Liu JX, YQ Wen. Simulation of waterway transit capacity at harbor based on ship behavior. Journal of Dalian Maritime University. 2009;35:31-33.

43. Liu Z, Liu J, Li Z, et al. Characteristics analysis of traffic flow and ITS mathematical model. J Mar Sci Technol. 2017;25(2):2.

44. Cunha AC, Brito DC, Brazil Jr AC, et al. Challenges and Solutions for Hydrodynamic and Water Quality in Rivers in the Amazon Basin. Hydrodynamics - Natural Water Bodies. 2012;67-88.

45. Wang N, Meng X, Xu Q, et al. A Unified Analytical Framework for Ship Domains. Journal of Navigation. 2009;62(4):643-655. 